\title{
Improving the accuracy of patients' expectations of the psychiatric out-patient consultation
}

\author{
B. C. Douglas, L. M. Noble and S. P. Newman
}

\begin{abstract}
Aims and method To investigate the impact of a video to improve the accuracy of patients' expectations of their first out-patient appointment. An intervention study was conducted in which patients watched a video before their appointment. The video provided information about the content of the consultation, the psychiatrist's role and types of treatments.

Results The intervention increased the accuracy of patients' expectations but had no impact on satisfaction or anxiety. The video was popular as a means of preparing patients for the consultation.

Cinical implications This could be offered routinely to patients attending services for the first time.
\end{abstract}

Patients referred to out-patient clinics may have misconceptions about what will happen when they attend (Skuse, 1975; Michaels \& Sevitt, 1978). Studies have found that patients' expectations are linked to drop-out rates (Baekeland \& Lundwall, 1975; Clinton, 1996; Bunn et al, 1997), satisfaction (Silverman \& Beech, 1979; Balogh et al, 1995) and outcome (Hansson \& Berglund, 1987). The need for current research into patients' expectations of psychiatric settings has been highlighted (Barker et al, 1996).

Interventions to improve the accuracy of patients' expectations of mental health services have resulted in improved attendance and satisfaction and decreased anxiety (Skuse, 1975; Spector, 1988; Webster, 1992). Of the different interventions studied, video has been found to be the most effective (Tinsley et al, 1988). Videos have been used successfully to prepare patients for psychotherapy (Deane et al, 1992) and the transition from in-patient to outpatient services (Hagan et al, 1983).

\section{The study}

Patients were recruited from a general adult clinic at an inner city hospital. To identify the issues to be included in the video, 19 patients were asked a series of open-ended questions about their expectations of the consultation, the psychiatrist's role and types of treatment. Three psychiatrists were asked about the format and content of their consultations at the clinic and for their views about patients' expectations and any misconceptions.

Patients expressed a range of expectations. There was confusion about the psychiatrist's role, whether psychiatrists are medically qualified and the difference between psychiatrists and psychologists. Many patients expected a short interview (15-30 minutes) and did not expect to be asked about their background, relationships or past medical history. The most commonly expected treatment was talking therapy, rather than medication. Patients expressed concerns about confidentiality, the stigma of mental illness and whether the referral implied that they were going mad.

A 10-minute video was produced that included a series of simulated clips of the initial consultation with points highlighted by a presenter. The main points included are given in Table 1 (a copy of the full script is available from the author upon request).

The study was a randomised comparison between patients viewing this video or a control video (attention placebo control). The control was a 10-minute video called 'The Meal Ticket' produced by the National Dairy Council in 1992, which provided information about healthy

Table 1. Points highlighted in the video

1. Role of the psychiatrist

2. Role of the patient

3. Causes of psychological problems

4. Content of the assessment interview

5. Confidentiality

6. Possible outcomes

7. Issues of the stigma of mental illness and patients' fears of 'going mad' 
eating. A video unrelated to mental health issues was chosen to ensure a neutral impact.

All new patients available to take part consented. The 48 patients were predominantly male $(63 \%)$, single $(63 \%)$, Caucasian $(88 \%)$ and unemployed (44\%), with an average age of 36 years and a diagnosis of depression (52\%); $63 \%$ had seen a psychiatrist previously, $38 \%$ had been admitted to a psychiatric hospital and $48 \%$ had a relative who had seen a psychiatrist. There were no significant differences between the experimental $(n=24)$ and control $(n=24)$ groups.

A measure of patients' expectations was devised to assess the impact of the video (Table 2).

Before watching either video, patients completed the State-Trait Anxiety Inventory (Spielberger et al, 1983) and the expectations questionnaire. After watching the video, the experimental group completed the State Anxiety Inventory, the expectations questionnaire and a question about the usefulness of the video. After their consultation, both groups completed the Client Satisfaction Questionnaire (CSQ-8; Larsen et al, 1979). The experimental group were also asked a question about the helpfulness of the video.

\section{Findings}

There was no significant difference between the experimental (mean 7.9, s.d.=1.3) and control groups (mean 8.1 , s.d. $=1.1$ ) in their initial expectations $(t=0.59$, d.f. $=46, P>0.05$, twotailed). After the video, the experimental group showed significantly more accurate expectations (mean 8.9, s.d. $=1.2, t=2.98$, d.f. $=23, P<0.01$, two-tailed). Patients with the maximum number of correct expectations rose following the experimental video from $2 / 24$ to $10 / 24$, and half of the group $(12 / 24)$ had more accurate expectations.

No significant differences were found between the groups initially for trait anxiety (experimental group: mean 53.1, s.d.=9.5; control group: mean
50.9, s.d. $=9.6 ; t=0.78$, d.f. $=46, P>0.05$, two tailed) or state anxiety (experimental group: mean 49.5, s.d.=11.6; control group: mean 46.3, s.d. $=9.7 ; t=1.0$, d.f. $=46, P>0.05$, twotailed) and there was no significant change in the state anxiety of the experimental group following the intervention (mean 47.7, s.d. $=11.7, t=1.3$, d.f. $=23, P>0.05$ ). There was no significant difference between the groups for satisfaction (experimental group: mean 25.0, s.d.=3.3; control group: mean 26.6, s.d.=3.4; $t=1.7$, d.f. $=46, P>0.05$, two-tailed).

Most patients found the experimental video useful $(16 / 24)$ and felt that it had prepared them for the consultation $(15 / 24)$.

Several patients said that the video was helpful in providing information and confirming the expectations already held. The clarification about confidentiality was highlighted as being particularly helpful. Of the 10 patients who had previously seen a psychiatrist, seven commented that the video would be particularly helpful for patients who had never had contact with psychiatric services.

\section{Comment}

The video improved the accuracy of patients' expectations. Although it did not significantly reduce anxiety or improve satisfaction, it did not have an adverse effect on either. Patients found the video helpful and this intervention could be offered routinely to new patients.

It was difficult to recruit patients due to nonattendance, and it was not possible to include only patients who had never had contact with psychiatric services. The patients who attended had reasonably accurate expectations. It may be that those who may have benefited most did not attend. This indicates that an intervention before attending could be beneficial (c.f. Skuse, 1975).

No established measure of patients' expectations of psychiatric services could be identified from the literature. Although the measure

\section{Table 2. Patient Expectations Questionnaire}

The patient was asked to circle 'Yes' or ' $N o$ ' in response to the following 10 statements to indicate what they expected to happen in the appointment:

1. The psychiatrist will ask me about my upbringing

2. The psychiatrist will not wish to know my opinions about the cause of my problems

3. The psychiatrist will not ask me about any physical illnesses I have had

4. The psychiatrist will ask me about any emotional problems I have

5. The psychiatrist will not be interested in any current relationships I have

6. My interview with the psychiatrist will be confidential

7. The psychiatrist will ask me about any medicines I am currently taking

8. The psychiatrist will write back to my family doctor after my appointment

9. I will definitely be given medication

10. The psychiatrist will have decided on the best treatment plan for me by the end of the first appointment 
devised was based on information from patients and psychiatrists, its reliability and validity were not empirically tested. A ceiling effect was observed, possibly due to patients' previous experience with psychiatric services.

A ceiling effect was also observed in satisfaction, which is not unusual (Elbeck \& Fecteau, 1990; Jones \& Lodge, 1991). Conceptual and methodological issues in the assessment of patient satisfaction have been highlighted recently and recommendations have been made for alternatives to traditional questionnaires (Uys et al, 1997).

Research with larger samples is needed to establish the effectiveness of a video in preparing new patients for their first consultation.

\section{Acknowledgements}

The investigators would like to thank the patients and staff at the out-patient clinic and The Priory Hospital, Roehampton, for funding B. C. D. during the research period.

\section{References}

BAEKELAND, F. \& LUNDWALL, L. (1975) Dropping out of treatment: a critical review. Psychological Bulletin. 82. 738-783.

BALOGH, R., SIMPSON, A. \& BOND, S. (1995) Involving clients in clinical audits of mental health services. International Journal of Quality in Health Care, 7, 343-353.

BARKER, D. A.. SHERgill, S. S., HigginSON, I., et al (1996) Characteristics of clients with schizophrenia who express uncertainty or uncertainty about continuing treatment with depot neuroleptic medication. Archives of Psychiatric Nursing. 11, 238-248.

BunN, M. H., O'CoNNOR, A. M., TANSEY, M. S., et al (1997) Characteristics of clients with schizophrenia who express uncertainty about continuing treatment with depot neuroleptic medication. Archives of Psychiatric Nursing, 11, 238-248.

Cunton, D. N. (1996) Why do eating disorder patients drop out? Psychotherapy and Psychosomatics, 65, 29-35.

Deane, F., SPICER, J. \& LEaTHEM, J. (1992) Effects of videotaped preparatory information on expectations, anxiety and psychotherapy outcome. Journal of Consulting and Clinical Psychology, 60, 980-984.

ELBECK, M. \& FECTEAU, G. (1990) Improving the validity of measures of patient satisfaction with psychiatric care and treatment. Hospital and Community Psychiatry. 41. 998-1001.
Hagan, L., Beck, N., KunCE, J., et al (1983) Facilltating psychiatric patient follow-up: a study of transfer attrition. Journal of Clinical Psychology. 39, 494-498.

HANSSON, L. \& BERGLUND, M. (1987) Factors influencing treatment outcome and patient satisfaction in a shortterm psychiatric ward: a path analysis study of the importance of patient involvement in treatment planning. European Archives of Psychiatry and Neurological Sciences, 236, 269-275.

JONES, L. \& LODGE, A. (1991) A survey of patients ' views of outpatient clinic facilities. Health Bulletin Edinburgh. 49. 320-328.

Larsen, D., AtTkisson, C., Hargreaves, W., et al (1979) Assessment of client/patient satisfaction: development of a general scale. Evaluation and Program Planning. 2. 197-207.

Michaels, R. \& SevitT, M. (1978) The patient and the first psychiatric interview. British Joumal of Psychiatry. 132, 288-292.

Silverman, W. H. \& Beech, R. P. (1979) Are dropouts, dropouts? Journal of Community Psychology, 7. 236-242.

SKUSE, D. (1975) Attitudes to the psychiatric out-patient clinic. British Medical Journal, 3, 469-471.

SPECTOR, K. (1988) Increasing take-up rate of clinical psychology services. Clinical Psychology Forum. 13. 11-13.

SPIElberGer, C., GoRBUCH, R., LUCHENE, R., et al (1983) Manual for the State-Trait Anxiety Inventory (revised edition). Palo Alto, CA: Consulting Psychologists Press.

TinSley, H., BOWMAN, S. \& RAY, S. (1988) Manipulation of expectancies about counselling and psychotherapy: review and analysis of expectancy manipulation strategies and results. Journal of Counseling Psychology, 35, 99-108.

UYS, L. R. THANJEKWAYO, L. \& VolkYwan, L. (1997) The measurement of quality of care in public sector psychiatric services based on consumer expectations. Curationis, 20, 25-32.

WEBSTER, A. (1992) The effect of pre-assessment information on clients' satisfaction, expectations and attendance at a mental health day centre. British Journal of Medical Psychology. 65, 89-93.

B. C. Douglas, Priory Lecturer, "L. M. Noble, Lecturer in Communication Skills, and S. P. Newman, Professor of Health Psychology. University College London, Department of Psychiatry and Behavioural Sciences, Wolfson Building, 48 Riding House Street, London W1N $8 A A$

*Correspondence 